\title{
Correction to: A numerical study of oil spill spreading in the Gulf of Thailand
}

Kittipong Srikhaetai ${ }^{1}$, Kittisak Chayantrakom ${ }^{1,2^{*}}$ and Wattana Kanbua ${ }^{3}$

\footnotetext{
"Correspondence:

kittisak.cha@mahidol.ac.th

${ }^{1}$ Department of Mathematics,

Faculty of Science, Mahidol

University, Bangkok, Thailand

${ }^{2}$ Centre of Excellence in

Mathematics, CHE, Bangkok,

Thailand

Full list of author information is

available at the end of the article
}

\section{Correction}

After publication of this article [1], it was brought to our attention that the article type should be "Research" rather than "Review".

\section{Author details \\ ${ }^{1}$ Department of Mathematics, Faculty of Science, Mahidol University, Bangkok, Thailand. ${ }^{2}$ Centre of Excellence in Mathematics, CHE, Bangkok, Thailand. ${ }^{3}$ Marine Meteorological Center, Thai Meteorological Department, Bangkok,} Thailand.

Published online: 02 September 2019

\section{References}

1. Kittipong, S., Chayantrakom, K., Kanbua, W.: A numerical study of oil spill spreading in the Gulf of Thailand. Adv. Differ Equ. 2019, 214 (2019). https://doi.org/10.1186/s13662-019-2143-z 